\title{
From STEM to STEAM: Strategies for Enhancing Engineering \& Technology Education
}

\author{
http://dx.doi.org/10.3991/ijep.v5i2.4458 \\ A.M. Connor, S. Karmokar and C. Whittington \\ Auckland University of Technology, Auckland, New Zealand
}

\begin{abstract}
This paper sets out to challenge the common pedagogies found in STEM (Science, Technology, Engineering and Mathematics) education with a particular focus on engineering. The dominant engineering pedagogy remains "chalk and talk"; despite research evidence that demonstrates its ineffectiveness. Such pedagogical approaches do not embrace the possibilities provided by more studentcentric approaches and more active learning. The paper argues that there is a potential confusion in engineering education around the role of active learning approaches, and that the adoption of these approaches may be limited as a result of this confusion, combined with a degree of disciplinary egocentrism. The paper presents examples of design, engineering and technology projects that demonstrate the effectiveness of adopting pedagogies and delivery methods more usually attributed to the liberal arts such as studio based learning. The paper concludes with some suggestions about how best to create a fertile environment from which inquiry based learning can emerge as well as a reflection on whether the only real limitation on cultivating such approaches is the disciplinary egocentrism of traditional engineering educators.
\end{abstract}

Index Terms-pedagogies, active learning, project based learning, inquiry based learning, engineering education.

\section{INTRODUCTION}

There is much evidence that instructional strategies that encourage undergraduates to become actively engaged in their own learning can produce levels of understanding, retention and transfer of knowledge greater than those resulting from traditional lecture/lab classes [1], however in many science and technology subjects there has been little adoption of student centric practices [2] despite evidence that the "sage on a stage" approach [3] is not as effective as alternatives. This paper focuses on engineering education, though many of the arguments can also be applied to other STEM subjects.

Developments in student-centric learning such as problem-based and project-based learning have so far had relatively little impact on mainstream engineering education [4], this could in part be attributed to a lack of understanding of the difference between these approaches, particularly when a project-based approach is mistakenly represented as problem-based ${ }^{1}$. It is not uncommon for project-based approaches to be based around specifications for a desired end product, and such fixed expectations can diminish the learner's role in setting the goals

${ }^{1}$ To avoid confusion in this paper, we avoid the use of the acronym PBL which is commonly used to refer to both project- and problembased learning. and outcomes [5]. When a project-based approach is mistakenly represented as problem-based, this situation is worsened as learners can consider themselves to be working in a specification free environment when in fact the tutor has a specific expected outcome in mind. The production of creative solutions to a problem outside of the scope of the project gives rise to the phenomenon of the "unexpected journey" [6]. When such journeys are encouraged and embraced they can be a fruitful learning experience, however when poorly managed the experience can be frustrating for learner and tutor.

The term "disciplinary egocentrism" describes the lack of student readiness to engage in multidisciplinary education [7], however the term can also be applied to academic staff who are unable or unwilling to engage in alternative approaches to their discipline. Disciplinary egocentrism encompasses two factors, negative relatedness and negative perspective. The first is a failure to see connections between a given discipline and an interdisciplinary subject or problem, which limits the ability to incorporate new ideas and practices. The second aspect is not only a rejection of other viewpoints, but often a failure to recognize differences in perspectives and contributions. It is quite likely that disciplinary egocentrism is as much present in academic staff as the student body and that this may be a factor in the slow adoption of new pedagogies in any discipline.

Whilst student-centric approaches are gaining popularity in STEM subjects, the liberal arts disciplines were early adopters of such approaches. It has been argued that engineering and technology should be reconfigured as academic disciplines, similar to other liberal arts disciplines [8]. This paper therefore suggests that an examination of liberal arts pedagogics may improve the uptake of studentcentric learning in STEM subjects. This paper draws on experiences integrating such approaches in a broader educational context and also critically examines literature related to this topic. It proposes a manifesto for the integration of arts based pedagogics to promote inquiry guided learning [9] in STEM subjects. The concept of STEAM education is emerging as a model of how boundaries between traditional academic subjects can be removed so that science, technology, engineering, arts and mathematics can be structured into an integrated curriculum [10]. Current work in STEAM education mostly focuses on secondary education; in this paper we propose that the tenets of the STEAM movement can be adopted in tertiary education where modularization and semesterization can produce barriers to integrative curricula.

Such barriers are perceived by some authors to no longer suit the world in which we live. Guy [11] argues that the $21^{\text {st }}$ century "has opened a new basis for holistic non- 
PAPER

FROM STEM TO STEAM: STRATEGIES FOR ENHANCING ENGINEERING \& TECHNOLOGY EDUCATION

linear design of complex systems", and also that "systems need to be investigated and tested as wholes, which requires a cross-disciplinary approach and new conceptual principles and tools. Consequently, schools cannot continue to only teach isolated disciplines based on simple reductionism". The experiences of the authors of this paper echo the words of Guy [11] who argues that in this complex world that understanding is more important than knowing, that learning by doing is a mechanism for gaining such understanding and that it is time to restore creativity into education curricula, particularly in disciplines not traditional considered to be creative. Such calls are not limited to STEM subjects, with the need for creative education in the field of business and management already established [12]. This paper extends previously published work [13] by introducing coverage of creativity as well as demonstrating the two-way advantages of integrating Arts and STEM subjects.

\section{BACKGROUND \& MOTIVATION}

The modern engineering professions are constantly exposed to many uncertainties, with clients, society, environmental groups, technology, government and rapid changing requirements of customers. This is a growing reflection of the changing world, which is increasingly complex and interconnected. To keep abreast with the fast pace of technological and organizational change requires new skills and understanding, not just the fundamental skills associated with a discipline but also the understanding of how to link information across multiple disciplines. To contribute to the current business environment and industry engineering graduates need to combine technical expertise with practical ability and commercial reality [14]. Despite these challenges, the dominant pedagogy for engineering education still remains "chalk and talk", despite the large body of education research that demonstrates its ineffectiveness [15]. Researchers have tried to develop various systems or guiding strategies to assist students in improving their learning performance and engagement [16] as a means to better prepare graduates for the challenges of real world problem solving.

Problem solving is just one element of the modern engineer, however the challenges faced by engineers in the current world can simply be generalized as the necessary capacity of knowing how, when and what to do to perform the ideal function in a given situation, including communicating the right information to the right person at the right time. This can be linked back to concepts such as dynamic memory [17], which in many ways articulate what the goal of modern education systems should be. Rather than train students to 'know' things, the goal should be to train students to 'understand' things. Understanding is about utilizing skills and competence, and contextualizing deeper knowledge. It requires action to assimilate the right concepts, to put them in situation. It is the concept of understanding that allows complex problems to be solved.

It has been observed that lecture based teaching does not advance problem-solving skills, does not require creative or critical thinking, and does not prepare students for the types of problems they will face as professional engineers [18]. It is perceived that lecture based teaching is limited that it does not promote higher order thinking and advanced reasoning skills amongst others. Both technical and practical skills are essential for students seeking to make careers in the industry [19]. Therefore in order to adequately prepare students for taking their place in their profession in the future there is a need to adopt alternative approaches to the education of engineers.

Traditional engineering instruction is deductive, beginning with theories and progressing to the applications of those theories [20], whereas arts based pedagogies are more inductive. Topics are introduced by presenting specific observations, case studies or problems, and theories are taught or the students are helped to discover them only after the need to know them has been established. A wide variety of inductive teaching methods exist, including inquiry learning, problem-based learning, project-based learning and discovery learning. The mismatch that exists between common learning styles of engineering students and traditional teaching styles of engineering professors is not a recent observation [21] which begs the question, why has there been no widespread adoption of inductive teaching methods in the engineering disciplines?

In engineering, the most-favored pedagogical model for teaching in an inductive style is project-based learning [22]. Project based learning is an approach to learning that focuses on developing a product or the creation of an artefact of some form. Whilst not formally defined as such, project based learning has the potential to embrace the principles of learning by doing [23], though the project may or may not be student-centered, problem-based, or inquiry-based as has been observed by de Graaf and Kolmos [24] who define three types of projects that differ in the degree of student autonomy:

1. Task project: Student teams work on projects that have been defined by the instructor, using largely instructor-prescribed methods. This type of project provides minimal student motivation and skill development, and is part of traditional instruction in most engineering curricula.

2. Discipline project: The instructor defines the subject area of the projects and specifies in general terms the approaches to be used (which normally involve methods common in the discipline of the subject area), but the students identify the specific project and design the particular approach they will take to complete it.

3. Problem project: The students have nearly complete autonomy to choose their project and their approach to it.

In many cases, it would seem that the "project based" approach in engineering is not implemented as a studentcentric, inquiry based model and indeed may be no more engaging that the chalk and talk approach. There is perhaps a confusion about the nature of inquiry [25] that contributes to the focus on projects. This is coupled with a predominant view that problem based learning or any degree of student-centric thinking may lead students to not "constructing the "right' knowledge." and that it may not be useful for engineering education with regard to "the acquisition of knowledge that can be retrieved and used in a professional setting" [26]. It is in this area where this paper makes a contribution, focusing on how the pedagogical aspects of delivery in arts programmes may be utilized in the engineering discipline. This need has been identified by other research [27] that clearly identified that creativity and innovation cannot be treated separately 
PAPER

FROM STEM TO STEAM: STRATEGIES FOR ENHANCING ENGINEERING \& TECHNOLOGY EDUCATION

from STEM, and 'arts' should be an integrating part of the puzzle that combines creativity and innovation into a unified whole. The emergence of models of innovation for the creative industries that are derived from the scientific method [28] offer some potential in this regard.

It is unclear why the perception persist that engineers are uncreative. With an ever increasing complexity surrounding engineering projects mounting as natural resources dwindle, the world population increases, the creativity and innovation necessary to address the big issues facing society will only increase in importance. It is important to note that creativity and innovation are not synonymous; there is a clear and important distinction between them. It is also important to note that creativity is a mental ability anyone is capable of, not just the artists among us and that creativity is an attribute that can be cultivated and developed [29].

Creativity is most often defined as the mental ability to conceptualize (imagine) new, unusual or unique ideas, to see the new connection between seemingly random or unrelated things, whereas innovation is defined as the process that transforms those forward-looking new ideas into real world enhanced value. Some authors have posed the question as whether engineers should strive to be creative as well as how to teach creativity in an engineering context [30]. Peters [31] argues that many groundbreaking design concepts stem from simple reformulations of current thinking and practice informed by observation outside of engineering paradigms, yet historically the suggestion on how to develop creative engineers has not explicitly involved the suggestion of considering disciplines other than engineering explicitly [32] and instead focuses on developing creativity through exercises in lateral thinking.

Whilst lateral thinking is an important skill, it is but one part of the puzzle in terms of developing creativity and innovation in an integrated element of a holistic engineering education. Bordogna, Fromm \& Ernst [33] argue that both lateral and vertical are important and that innovative engineers require a range of capabilities, namely an integrative capability, an analysis capability, an innovation/synthesis capability and finally a contextual understanding capability. They go to argue that it might be possible to define modern engineering as the "process of correlation exactitude with chaos to bring vision in to focus" and suggest that such a construct can be achieved through unifying the functional core of an engineering process with the liberal arts, and developing an integrated learning process that is followed throughout the delivery of engineering programmes. The development of approaches to foster and enhance creativity is becoming apparent in the educational research literature [34].

It is important to consider a number of questions. Firstly, does a constructivist or inductive teaching pedagogy have to limit itself to one "label"? In an engineering context, can a project based learning environment also be problem based and inquiry based at the same time? Secondly, to what extent does student-centric methods and involving the student in defining the problem detract from the ability to "learn the right things"?

Studio based learning [35] is common in the creative arts and is based around a cycle of proposing, critiquing and refinement of ideas and artefacts. Studio deliveries strongly emphasize learning by doing, and recognize that people must actively participate in doing things, in order to assimilate and accommodate information, which has long been acknowledged by psychologists [36]. Studio based approaches emphasize the use of formative assessment and are often based around promoting critical reflection and learner autonomy. There have been some attempts to introduce formative assessments into engineering programmes [37], though the use of online and anonymous tools are at odds with the more individualized and personal assessment events common in arts disciplines. This differs very much from the traditional approaches in engineering education. Core to the studio approach is an understanding that delivery may contain some or all aspects of problem, project, inquiry and discovery based learning and that this balance may change over time as different projects happening in parallel mature at different rates. This obviously produces challenges for educators working in a studio model. Whilst the studio model is common to creative arts and architecture, it is emerging as a feasible approach in computing and software engineering education [38] and as such is worthy of consideration across a wide range of STEM subjects. Some attempts have been made to adopt studio approach in engineering which suggest that "the studio method can be very effective in teaching design concepts, but because students are likely to be unfamiliar with this approach, care must be taken to reassure students regarding grades and expectations" [39].

The raising of unfamiliarity is an interesting point as in many cases it is not just students who are unfamiliar with the approach, engineering educators may also feel wary of adopting an alternative approach. Issues that have been observed with educators comfort with adopting an online delivery [40] are just as applicable to those transferring between different styles of classroom delivery.

Educational researchers have identified a number of principles of learning that provide additional insight into what makes people learn most effectively. Edward Thorndike developed the first three "Laws of learning", namely readiness, exercise, and effect [41] which have since been extended with five additional principles, namely primacy, recency, intensity, freedom and requirement. These principles of learning can be used to explain who people learn, for example the principle of primacy suggests that the concepts that people learn first make a stronger impression than contradictory concepts learnt later, giving rise to the phenomenon that it is "hard to unlearn" [42]. Similarly, the principle of recency suggests that knowledge recently utilized is easier to recall.

The role of these learning principles also plays a part in how educators choose to teach. Research from 2004 suggests whilst initial training of university teachers is becoming increasingly common that only three countries, the UK, Norway and Sri Lanka, had all universities promoting some form of training [43]. Given that many university educators come through a $\mathrm{PhD}$ and straight into teaching with little or no formal training on how to teach, it is not surprising that the law of primacy kicks in. It has been observed that "teachers teach the way they were taught" [44]. New educators tend to adopt a delivery method that is within their comfort zone, or more specifically they teach in the same way that they were introduced to particular topics or subjects. Over time the law of recency reinforces this behavior and gives rise to the presence of disciplinary egocentrism, or simply the view that "this is the way it works in engineering". 
The experiences of the authors of this paper are different. Each has come through an alternative route, either involving a change of discipline, the teaching of engineers in a non-engineering subject or the involvement in teacher training that involves educators from a wide range of domains. Common to these experiences is exposure to different ways of thinking and approaching education that has resulted in a belief that engineering education can be different. In particular, all of the authors feel that the core pedagogic values of the arts disciplines can play an important role in STEM subjects. These values place the student at the heart of the learning experience and support the student in terms of defining their own learning journey, which becomes a vehicle for introducing disciplinary knowledge. The next section presents a number of case study projects that demonstrate the effectiveness of more inductive approaches to education for engineering and design.

\section{CASE StUdy PROJECTS}

The following sections each outline a project design and implementation that is intended to engage students and capture their interest, whilst at the same time ensure that students are also exposed to and learn key skills or knowledge. Each of the projects differ in the extent to which they deploy arts pedagogical knowledge in terms of the design of the delivery, and each can be characterized by a different active learning approach, as shown in Table I.

\section{A. Poetry in Motion / Mechanical Ecologies}

"Poetry in Motion" is an example of a typical first year project in the Bachelor of Creative Technologies degree that encapsulates a wide range of theoretical and conceptual elements into a unified whole. The project is designed to implicitly introduce students to a range of design and manufacturing technologies and principles whilst also allowing students to define their own goals. It is an example of project based learning that includes, but is not dominated by a student-centric component.

The project was inspired by the popular 1960's board game, Mousetrap, in which players co-operate to build a working Rube Goldberg-like mousetrap. Once the mousetrap has been built, players turn against each other and attempt to trap their opponents' mouse-shaped game pieces. The overall goal of the Poetry in Motion project is to design and create a chain reaction game using imaginative and interesting combinations of basic mechanical systems. The project allows students to define their own project in such a way that it does not detract from the base skills and knowledge they are expected to develop. Overall, the project is designed to promote risk taking as well as achieve a practical appreciation of principles of physics and mechanics. The project is structured in two parts, the first being the creation of a simple mechanical automata that is designed using CAD software and then manufactured by utilizing the laser cutters in the Faculty fabrication facility. A typical mechanical automata is shown in Fig. 1.

This part of the project ensures that students understand that the practicalities of motion of manufactured parts may differ from simulated motion in the CAD software, often in catastrophic ways with mechanisms failing to operate. Such a "failed" project is often a successful learning experience and the failure is in no way penalized by careful structuring and consideration of the assessment, particularly the use of formative assessment. In most cases, students who produce an automata that fails to operate go on to demonstrate the value of the awareness this brings by applying more reasoned design approaches in the second part of the project.

Upon completion of the first stage of the project, students are encouraged to let their imaginations run wild in the design and implementation of their chain reaction game, applying what they have learned about how mechanical systems work in practice. The outcomes of the project are predictably variable, however the majority of students find motivation through the ability to define and create their own game scenario. A typical project outcome is shown in Fig. 2.

TABLE I.

PROJECT CHARACTERISTICS

\begin{tabular}{|l|c|c|c|c|c|}
\hline \multirow{2}{*}{ Project } & \multicolumn{5}{|c|}{ Pedagogical Characteristics } \\
\cline { 2 - 6 } & $\begin{array}{c}\text { Delivery } \\
\text { Model }\end{array}$ & $\begin{array}{c}\text { Problem } \\
\text { Based }\end{array}$ & $\begin{array}{c}\text { Project } \\
\text { Based }\end{array}$ & $\begin{array}{c}\text { Inquiry } \\
\text { Based }\end{array}$ & $\begin{array}{c}\text { Discovery } \\
\text { Learning }\end{array}$ \\
\hline $\begin{array}{l}\text { Poetry in } \\
\text { Motion }\end{array}$ & Studio & & $\checkmark$ & & \\
\hline $\begin{array}{l}\text { Experience } \\
\text { Design }\end{array}$ & Lectorial & $\checkmark$ & $\checkmark$ & & \\
\hline $\begin{array}{l}\text { Haptic } \\
\text { Glove }\end{array}$ & Studio & & $\checkmark$ & $\checkmark$ & $\checkmark$ \\
\hline EWB & Lectorial & $\checkmark$ & $\checkmark$ & $\checkmark$ & \\
\hline Flying High & Studio & & $\checkmark$ & & \\
\hline
\end{tabular}

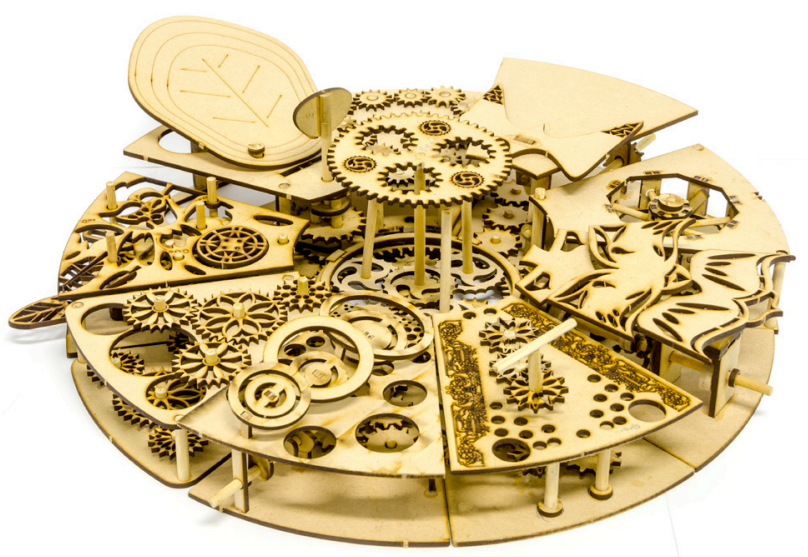

Figure 1. Sample automata

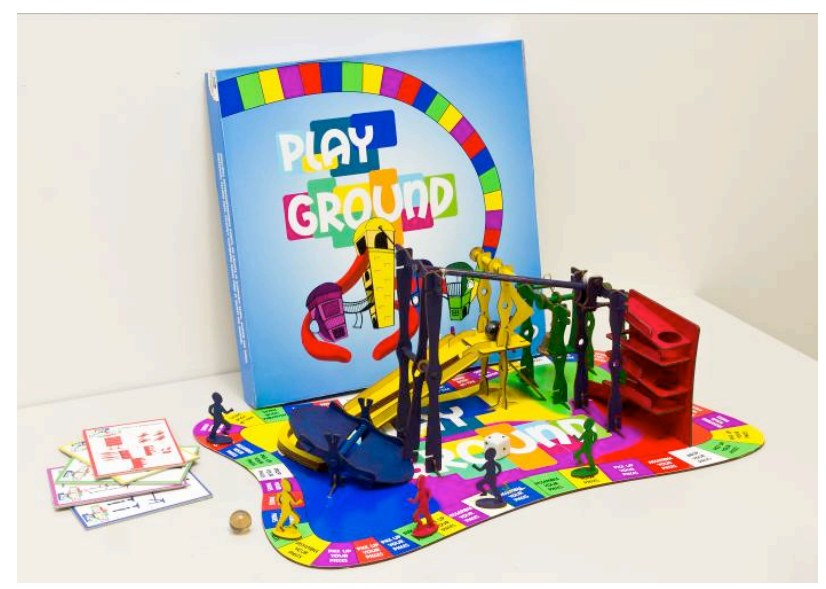

Figure 2. Sample finished project 
PAPER

FROM STEM TO STEAM: STRATEGIES FOR ENHANCING ENGINEERING \& TECHNOLOGY EDUCATION

In the process of designing the game, the students reapply the CAD skills and knowledge gained in the first part of the project, therefore providing the opportunity to reinforce the learning outcomes. To many engineering educators, it is possible that the development of game may seem both childish and frivolous. However, the project demonstrates a good example of how a simple change in philosophy can motivate and encourage students by providing them with a context for their learning. In this project, students effectively learnt a range of practical engineering principles and skills, namely a solid introduction to design foundations and CAD, an understanding of the limitations of machinery dynamics and an ability to translate design intent into a finished product through a CAM facility. Of particular interest is the first stage of the project, where students attempted to design small mechanisms often based around gears. Whilst a typical approach to teaching gear design in an engineering course would start with the Fundamental Law of Gearing, that the angular velocity ratio between two gears of a gearset must remain constant throughout the mesh period. This would then be followed by in introduction to the involute profile and calculations for gear design, including correct meshing criteria. It is questionable whether this approach creates a "need" to learn, whereas the approach where students build a gear train that ultimately may not work is an alternative process where a need to learn is developed and this has the potential to start students on a journey driven by their curiosity.

\section{B. Experience Design}

The project called 'Experience Design' was a ten-week project at Auckland University of Technology undertaken by 22 Bachelor of Business students (majoring in Design). Students were encouraged to use problem based and participatory approach of learning. Given the short period and the complexity of the projects, students were provided with a structured design process and a set of design methods. During the course, students were required to identify and explore the needs of elderly users, and understand their strengths and limitations in using the intended products. Students were required to identify a problem and design a creative solution using participatory approaches. The project also assisted students to engage with broader contextual and social issues in creating innovative concepts. Students were encouraged to use visual storyboarding and digital storytelling of the solution to the users. In this project problem based learning had an effective outcome for most of the students. It helped them to come close and align their thinking with the reality. Examples of visual storytelling are shown in Fig. 3 and Fig. 4.

The practical and design method of working on project helped students to experience the real world and tackle an actual problem. It helped students to better engage in their learning process. This pedagogy of learning by doing, can also be successful integrated in engineering teaching where young engineers are prepared to practice innovative thinking and behavior by engaging with a real world situation.

\section{Haptic Glove}

This project is another example from the Bachelor of Creative Technologies degree and can be used to highlight a number of interesting issues. This project was conducted by two students, one in their second year and one in their

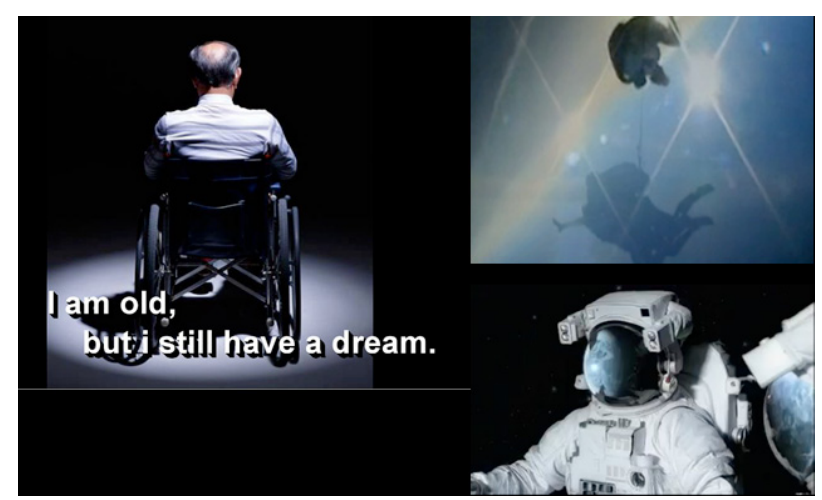

Figure 3. Virtual reality experience visual board

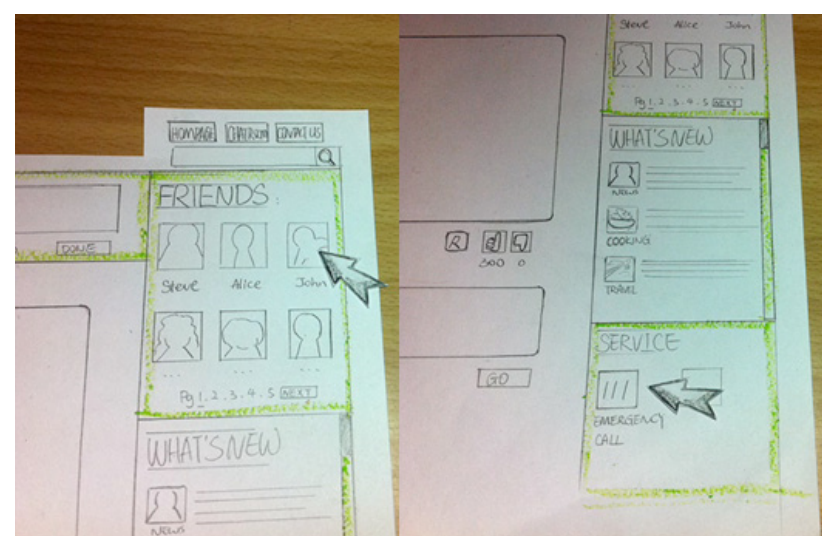

Figure 4. Storyboard of social networking system

third year of study. As such, it is a good example of the effectiveness of structuring vertical course deliveries that mix students from different year groups to promote peer learning [45]. The project evolved from one student's interest in the changing relationship between humans and objects. The second student was mostly interested in game development. By actively discussing potential overlaps in two very different interests, the student elected to develop a game controller that blurred the boundaries between the player and the game by facilitating a two way data exchange. As well as controlling the game play, the controller provides haptic feedback based on game events.

From an education perspective, this project is an interesting case as the self-motivated students were provided minimal guidance in their project and this is an example of discovery learning. Such minimal guidance methods have been criticized in the literature [46], however the use of vertical orientated delivery allows more experienced students to provide guidance and support to less experienced ones. Guidance was provided to the team by taking advantage of this and another curriculum innovation in the degree, the stretching of projects across multiple courses. The third year student was enrolled in a new, experimental course called a "research practicum" that is based on a research apprenticeship model. Within this semistructured learning environment the student was provided with insight into the research process and guided through the conduct of a systematic literature review that was used to inform the development of the device. The research practicum was particular effective as it nurtured the peer learning process and also led to the submission of two research papers from the project [47]. Allowing a vertically orientated delivery, stretching projects across multiple 
courses and encouraging undergraduate students to engage in rigorous research has create a unique blurring between undergraduate, postgraduate and staff that is effective in both driving learning and generating research momentum. In a twelve week semester, the two students prototyped a number of technology based solutions that combined to produce a working prototype of a wearable haptic feedback device as shown in Fig. 5.

The combination of guided discovery based with the student-centric project produced a truly inquiry based learning process. By not constraining the project in any way, the students tried things out, prototyped solutions and came up with creative solutions to difficult problems. There were of course mistakes and failures along the way, but these should also be considered positive learning experiences. For example, the first prototype of the glove used an Arduino Uno microprocessor with the circuitry assembled using a solderless breadboard. This of course resulted in a bulky solution. The students decided to develop a custom printed circuit board (PCB) and set out to learn how to achieve this. In this process, the students designed their PCB around the footprint of the surface mounted chips based on the manufacturer's datasheet. However, they had neglected to consider the orientation of the chips which resulted in the pins not matching the PCB circuit - the student though the datasheet was looking top down, but the datasheet had the pinout represented bottom-up. This resulted in a painstaking soldering endeavor to correct the mistake, in this case a mistake the student will not make again. It is our belief that mistakes are inevitable, and had the student not made the mistake in the relatively safe learning environment that that it could have occurred later in their career when the implications of such a mistake could have been more costly.

\section{Engineers Without Borders (EWB)}

The EWB project is part of the 'Introduction to Design' course which is a core course for both the Bachelor of Engineering Technology and Bachelor of Engineering (Honours) degrees at Auckland University of Technology. The course develops effective communication skills in an engineering design context, using a variety of media. It further develops an understanding of the role and responsibilities of an engineer in society.

The pedagogy used for this course is different to that of traditional engineering subjects where students passively receive information from the lecturer. Overall the approach is one of active learning. The design element is essentially covered by students completing tutorial problems individually or in groups with the aid of a facilitator, essentially a variation on the studio-based learning approach.

The EWB Challenge could be considered either as a project based learning, problem based learning or inquiry based learning. Certainly it is intended as a project based learning framework driven by a poorly defined problem statement. However, for most of the groups this problem based learning stimulated a deeper engagement that enabled these teams to transition in to an inquiry based learning mode as their interest and their commitment to the project developed. Certainly the groups were encouraged to develop their projects in this way. Given there is general confusion about project based learning and problem based learning, this case study provides a useful opportunity to clarify how the various approaches

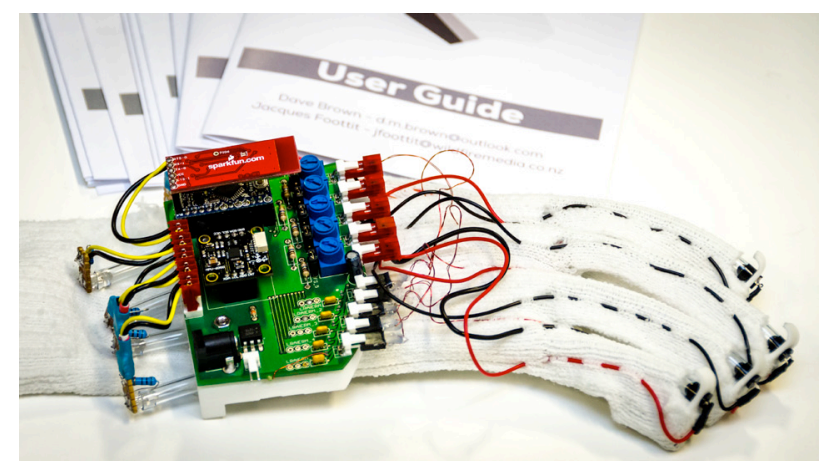

Figure 5. The finished haptic glove

are related. We consider problem based learning to be a subset of inquiry based learning, which itself is a subset of active learning [48]. However, not all problem based or inquiry based approaches are necessarily project based learning. Project based learning is another subset of active learning that overlaps with problem based learning.

The EWB Challenge is a fantastic opportunity for students to learn about and understand different cultures and be involved in an exciting time of change for the region selected for that years challenge. This year the area is a rural hill top communities in the Gorkha District of Nepal. It presented an opportunity to learn, not just about the challenges facing their communities, but also about community development in general, and the role engineers and other technical professionals can play. Engineers without Borders (EWB) is working towards the goal of a transformed engineering sector so that every engineer has the skills, knowledge, experience and attitude to contribute towards sustainable community development and poverty alleviation. The EWB Challenge program aims to contribute to this broader goal by working at the university level to create change within engineering curriculum and help to shape future engineers by achieving the following objectives:

- Introduce first year engineering students to concepts of humanitarian engineering by working on real world development projects

- Empower university students to gain an increased awareness of the role of engineers in poverty alleviation and their individual responsibility as global citizens

- Support EWB's community based partner organisations work by providing access to engineering student design ideas and by supporting them to share knowledge and resources with universities internationally.

The students were asked to form groups of four and select a design area for their project. Design areas included but are not limited to housing \& construction (Fig. 6), water supply \& sanitation systems (Fig. 7), energy, waste management, climate change, information \& communications technology or transportation.

The groups provided design solutions for projects using the village of Sadhikhola as a case study. They could address a single issue or provide an integrated design solution for two or more areas, or even propose an alternative project. The EWB Challenge is an open-ended learning experience and the breadth and depth of design is left to the groups to decide. Students received a briefing for the scenario which included a presentation by EWB per- 
PAPER

FROM STEM TO STEAM: STRATEGIES FOR ENHANCING ENGINEERING \& TECHNOLOGY EDUCATION

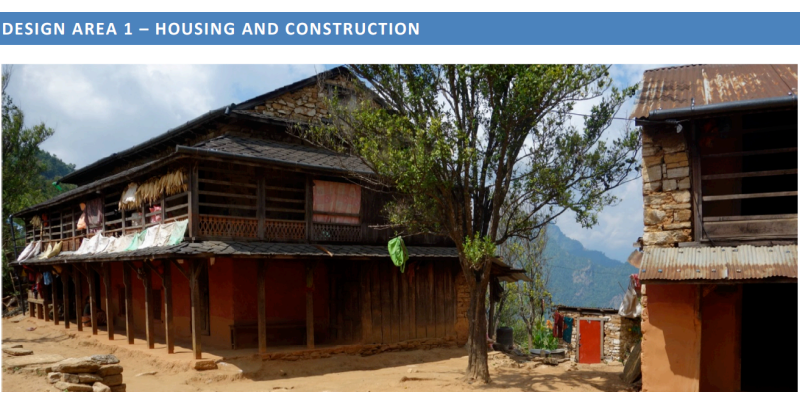

Figure 6. Housing in Sandikohla, 2013

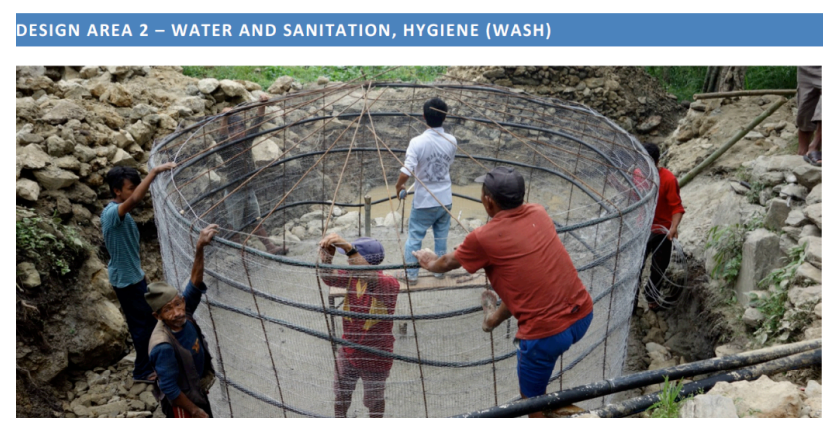

Figure 7. Constructing a new rainwater tank in Sandikohla, 2013

sonnel about the area and its problems. A resource pack was also made available. It was anticipated that there would be significant further resources accessed on line by the groups.

The course was not entirely project based and during weekly lectures time was made available for the groups to communicate the progress on their projects. A facilitator was available to clarify and advise on specific issues. Each group was expected to meet for non-facilitated meetings between lectures at which they discussed their understanding of the scenario, shared their current knowledge and ideas on the topics involved, made decisions on how to address the project, identified what topics or learning objectives they needed to research in order to progress, allocated who was going to investigate which topics, planned for contact between scheduled sessions and reflected on their actions and progress

Throughout the project students were encouraged to be creative in their solutions and to document any assumptions in the final report. The project based learning activity was assessed in two ways. Firstly by a group presentation in which all members were expected to participate fully and secondly by way of a project report. A single group mark was awarded to all group members. Where a group member had not participated fully their mark was adjusted accordingly.

Around 100 projects were completed. All were of good standard, some were exceptional. Some groups and individuals were extremely well motivated and developed valuable research skills preparing them well for life-long learning. Most of the students achieved learning outcomes that included critical thinking, ability for independent inquiry and the responsibility for own learning and intellectual growth.

While no evidence proves that problem based learning enhances academic achievement as measured by exams, there is evidence to suggest that problem based learning "works" for achieving other important learning outcomes. Studies suggest that problem based learning develops more positive student attitudes, fosters a deeper approach to learning and helps students retain knowledge longer than traditional instruction. Further, just as cooperative learning provides a natural environment to promote interpersonal skills, project based learning provides a natural environment for developing problem-solving and life-long learning skills.

\section{E. Flying High}

The Flying High project was a first year project in the Bachelor of Creative Technologies degree. This particular project has been included to show that the integration of Arts and STEM subjects is in fact a two way dialogue. It is important to realise that the teaching of STEM subjects is not inherently flawed, and correspondingly that the teaching of Arts subjects is inherently better. It is the belief of the authors that both elements can learn from each other in an integrative manner.

The Flying High project was designed to target "creative" students and provide them with exposure to more systematic methods of design commonly associated with engineering delivery. The project also introduced more objective evaluation techniques as an approach to maintaining a level of criticality in decision making. However, the project still maintained an active learning approach and supported the principles of learning thinking by creating an environment where a need to learn was established.

The project was conducted in two parts, the first part being based around the building of an ornithopter. Students were provided with instructions on how to build a simple ornithopter and encouraged to develop their own design by extending the basic instructions. Such extensions ranged from the shaping of structural elements and the modification of tail sections as shown in Figure 8.

More complex variations were produced, including ornithopters designed around the flight dynamics of dragonflies or a variety of bi-wing designs. The teams were tasked with producing an ornithopter that would either fly the greatest distance or to maintain flight for the longest duration and the first phase of the project culminated in a fun and engaging competition, where most ornithopters were not particularly successful.

The "failing" of most ornithopters created a fertile learning environment as most students became curious as how to make something fly. The second part of the project opened up with an introduction to topics that would normally be considered of relevance or interest to artists which included fluid dynamics and flight mechanics.

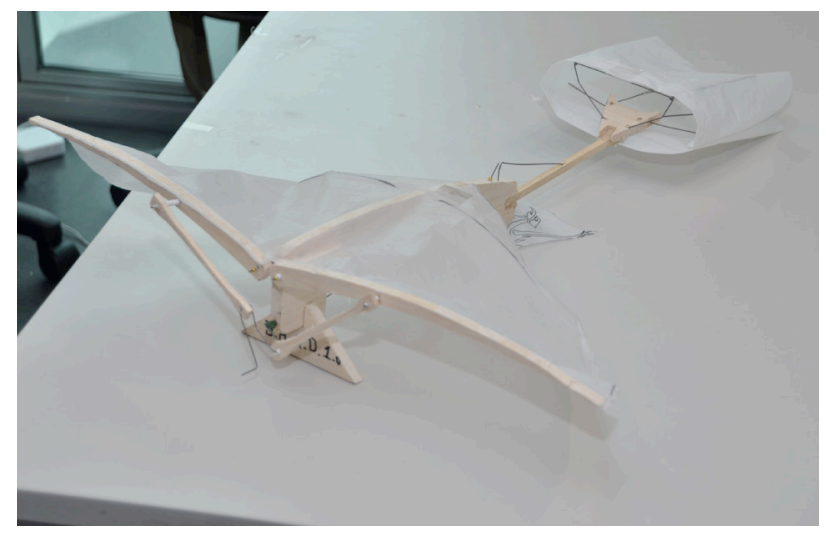

Figure 8. Simple ornithopter 
Whilst only covered at conceptual level, it was observed that most students became engaged and interested enough to ask for more detailed discussion and analysis of the topics, which naturally led in to the main aspect of the second part of the project - how do you design something to fly? In this regard, the main focus was about design and design methods rather than flying. There is a distinct difference between engineering design and "creative design", with the former being process driven and the latter almost considered to be a black box from which concepts emerge. The purpose of the project was to introduce concept generation and evaluation techniques from engineering design into a creative design process.

Two particular techniques were introduced, namely morphological analysis [49] to generate concepts and Pugh's method [50] for evaluating concepts. Morphological analysis is based around the principle of a functional decomposition of a need for which concepts are generated to implement that particular function, different concepts are then combined to produce a range of overall design concepts. The students were briefed that their flying machines needed to have some grounding in reality, but could be allowed to stretch current technological limitations and be very much future focused concepts. Typical morphological charts generated by the students are shown in Figure 9 and Figure 10.

Analysis of the charts shows that whilst there was an interest in understanding how things fly, that this was not fully realized in practice. For example, it was common to see that propellers were considered to be a means of producing lift, as in Figure 9. However, this did not limit the students in applying a process driven approach to stimulate their own inherent sense of creativity. Many students commented with surprise on the range of distinct solutions developed by a method that they initially thought would limit rather than stimulate creativity. Students typically selected a number of different concepts from their morphological chart and then evaluated them using Pugh's method, as shown in Figure 11.

Feedback from students indicated that they found the methods intuitive and easy to apply, though a small minority indicated that they morphological approach was a barrier to "achieving the design that they wanted to get". In that regard, it seems that irrespective of discipline that some students simply do not want to explore multiple concepts.

The true measure of the degree of engagement comes from an analysis of later projects, where the same cohort of students was tasked with designing a visual arts project and a number of students chose to apply the morphological approach to their arts practice.

\section{DISCUSSION}

The previous section has outlined five very different project implementations all of which are related to design, engineering and technology. Each of the projects is intended to be student-centric as a means to motivate students to take ownership of their own learning experience. This approach is much more common in arts disciplines, where much of the teaching is conducted in studio based deliveries that encourage active learning. Whilst the STEAM movement encompasses a wider integration of disciplines, our focus is extracting guidelines from our

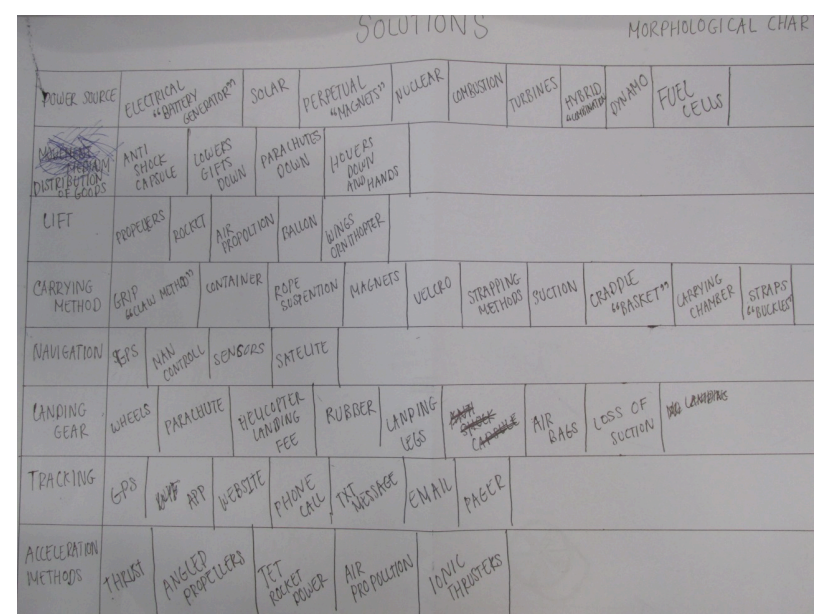

Figure 9. Morphological chart \#1

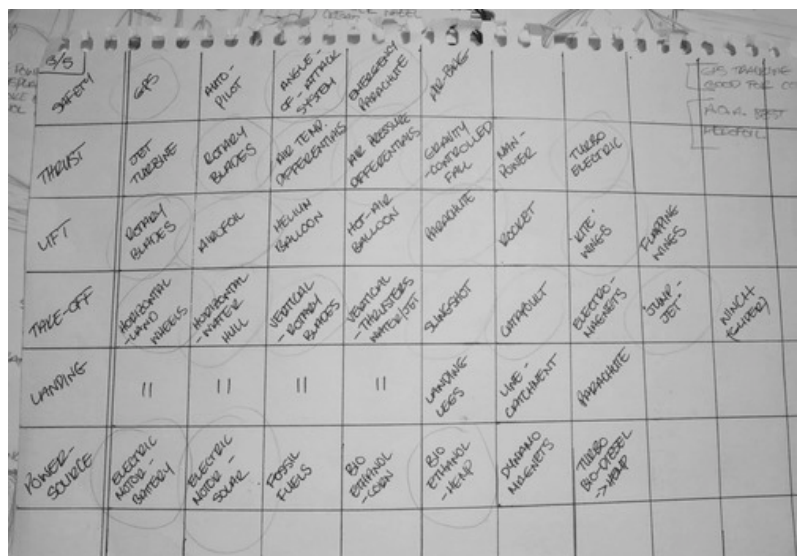

Figure 10. Morphological chart \#2

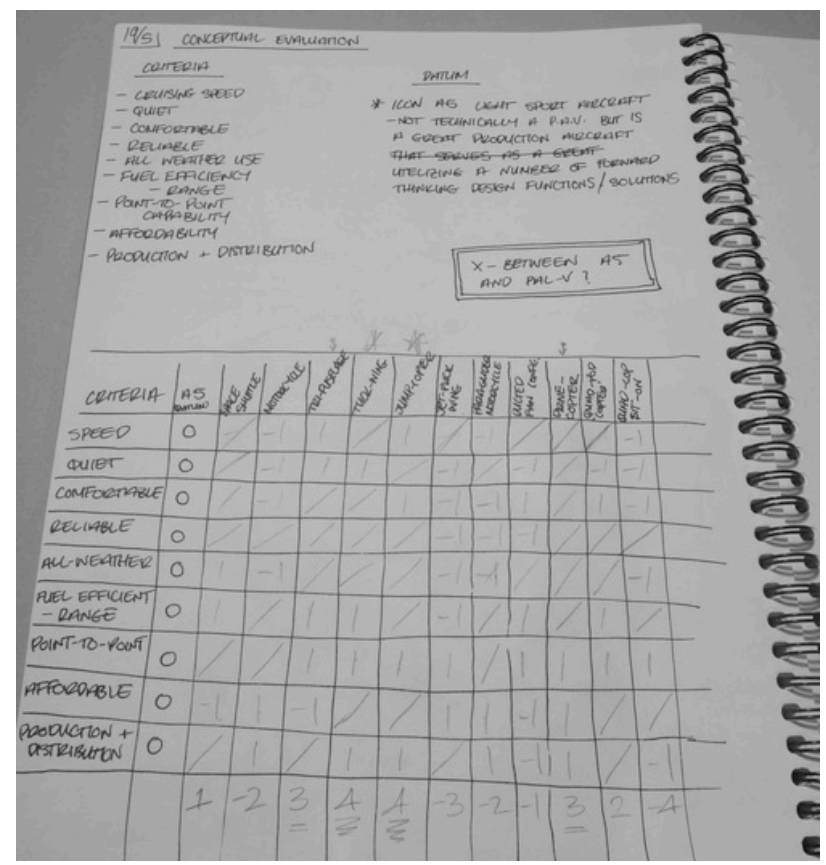

Figure 11. Evaluation matrix

experiences of using arts pedagogics in non-arts disciplines, particularly in a modularized tertiary environment.

All of the projects outlined in this paper embrace the principles of active learning, but are different in terms of 
PAPER

FROM STEM TO STEAM: STRATEGIES FOR ENHANCING ENGINEERING \& TECHNOLOGY EDUCATION

whether they are implemented as problem based, project based, inquiry based or discovery based. Indeed, within any one of these projects the learning characteristics of teams will differ. The intention of all of the projects is to create "fertile ground" in which a student may discover their own curiosity that then drives their learning experience.

There are a number of challenges that exist in developing active learning approaches in an engineering curriculum, many of which lie in engineering educators needing to look beyond their own experiences for inspiration on how to implement active learning in their courses. The following sections outline a number of guidelines that can be considered that are drawn from a broad experience base in designing projects such as those outlined in this paper.

\section{A. Embrace Different Disciplines}

One of the main challenges to overcome is going to be the implicit perception of the engineering discipline itself that active learning is somehow "not right" for engineering. This view arises from the presence of disciplinary egocentrism that creates a bias towards more traditional approaches. To cross those disciplinary boundaries, engineering educators should consider whether they have an option to teach (or co-teach) in an alternative discipline or whether they can bring in staff from another discipline in to their course. For example, in the teaching of engineering design it would be perfectly feasible to bring in staff who teach product or industrial design, both of which are often taught using a studio model that can inform the delivery of engineering design courses. One of the key concepts of active learning is the process of "learning through doing" and engineering educators need to not be dismissive of the unknown, but to try something and see where it leads. As highlighted in the "Flying High" project, there is of course potential whereby engineers can also inform and improve the delivery of arts courses.

\section{B. Design Projects for Students}

For a project based learning environment to have any possibility of inspiring a wide range of students and motivating them to take control of their learning experience then the project needs to be designed to be flexible enough to accommodate different student interests. This doesn't necessarily mean an open ended project. For example, the "Engineers Without Borders" project outlined in this paper allows students control of the content of their work but in such a way to ensure they don't "learn the wrong things". Similarly, the "Flying High" allowed students to identify their own goal in terms of their design and only constrained the students to using a particular approach.

\section{Tease out Creativity}

Creativity is closely tied with divergent thinking, a cognitive skill that is different to general intelligence. Whilst current early childhood education has undergone a renaissance in terms of promoting divergent thinking this has yet to fully penetrate secondary or tertiary education. As a result, students may feel that their more creative ideas won't match the expected answer. It can be useful to transform the teaching environment in to a different "play space" to allow students to safely explore how to be creative, whilst simultaneously undertaking activities that are specifically designed to stimulate creativity. As an example, when teaching engineering design it may be appropri- ate to undertake a different design problem, perhaps something in experience design, where students can be encouraged to explore more freely. It is also useful to provide students with tools and techniques that promote exploration, such as early introduction of concept generation methods.

\section{Allow and Encourage Failure}

A project that fails doesn't necessarily mean that the student hasn't learned something valuable. Students will generally learn more by trying something that doesn't work than listening to an example of something that didn't (or did) work. To allow failure to occur, engineering educators need to reconsider how they design assessment events to not penalize experimentation and creative ideas that don't work in the short term, but lead to a greater understanding in the long term. In particular the inclusion of formative assessment events can have a positive impact on the learning experience. However, this thinking can be extended to consider how to support students to become critical, reflective practitioners. The use of digital portfolios and the use of design journaling can enhance this and also provide evidence of original work and thought.

\section{E. Realise Students are Different}

Not all students are going to react to active learning in the same way and many students will have different levels of achievement in terms of their learning experience. Promoting active learning doesn't mean leaving students to attempt to discover knowledge entirely on their own, whilst this may work for the strongest students it will rarely work for the majority. It is important to realize that there is no perfect journey, that students will progress at different paces and that educators need to shift gears regularly as they tailor the process of critiquing and refinement to different groups of students to encourage them on their journey of inquiry.

\section{F. Consider Vertical Orientation}

Many engineering programmes have a very strict progression model where students at different stages of study rarely mix. Whilst in many cases there are good reasons for this, actively encouraging the mixing of different year groups to work together on the same project can promote an entirely different learning experience. Even if this is not feasible in formal courses, consider whether it can be achieved through non-assessed mechanisms such as external projects.

\section{G. Explore Horizontal Blurring}

Again, many engineering programmes have very strict demarcation of topics that can create a limited view of how the topics are interrelated. Institutionally, this demarcation provides convenience as student performance in any given course is relatively easy to determine. However, allowing projects and assessments to stretch over multiple courses opens a wealth of opportunities. Firstly, it allows educators to provide multiple strands of guidance to students working on projects that come together to allow a student to achieve a better outcome. Secondly, it allows students to see the interrelationship between topics that are otherwise obscured. This becomes important when a student is enthused and excited about one aspect of their learning journey, which can spill over into another topic that otherwise would not be found enjoyable. 


\section{H. Have Higher Expectations}

Raising expectations for student achievement will exert powerful influences upon the student learning experience. Expectations need to be reasonable, but should also be aspirational and accompanied with appropriate support and encouragement. Students are very capable of producing work to a high standard when motivated. Educators should assist students to seeing the potential for all subjects to be interesting.

\section{CONCLUSION}

This paper has outlined a number of student projects related to technology, engineering and design disciplines that have been designed to promote active learning in the participants. Such active learning is currently rare in engineering education, which may possibly be attributed to the presence of disciplinary egocentrism in engineering educators. However, such approaches are more common in the arts disciplines where students are encouraged to be more explorative. Some of the common themes that have emerged from the authors' experience in implementing active learning have been extracted into a set of guidelines or considerations on how best to approach the implementation of active learning in engineering. The most important guideline is that of seeking experience outside of traditional engineering teaching to inform a possible direction. The goal of implementing active learning should be to provide an environment where it is possible for students to become excited, curious and to take control of their own learning experience. The projects outlined in this paper show that this achievable in the engineering discipline and that it is possible to embrace creativity in the education of future engineers.

\section{REFERENCES}

[1] T. R. Lord, "A comparison between traditional and constructivist teaching in college biology," Innovative Higher Education, vol. 21, pp. 197-216, 1997. http://dx.doi.org/10.1007/BF01243716

[2] R. L. DeHaan, "The impending revolution in undergraduate science education," Journal of Science Education and Technology, vol. 14, pp. 253-269, 2005. http://dx.doi.org/10.1007/s10956-005-4425-3

[3] A. King, "From sage on the stage to guide on the side," College teaching, vol. 41, pp. 30-35, 1993. http://dx.doi.org/10.1080/ 87567555.1993.9926781

[4] J. E. Mills and D. F. Treagust, "Engineering education-Is problem-based or project-based learning the answer?," Australasian Journal of Engineering Education, vol. 3, pp. 2-16, 2003.

[5] J. R. Savery, "Overview of problem-based learning: Definitions and distinctions," Interdisciplinary Journal of Problem-based Learning, vol. 1, p. 3, 2006. http://dx.doi.org/10.7771/15415015.1002

[6] A. M. Connor, C. Berthelsen, S. Karmokar, B. Kenobi, S. Marks, and C. Walker, "An Unexpected Journey: Experiences of Learning Through Exploration and Experimentation," presented at the DesignEd Asia Conference, Hong Kong, 2014.

[7] D. M. Richter and M. C. Paretti, "Identifying barriers to and outcomes of interdisciplinarity in the engineering classroom," European Journal of Engineering Education, vol. 34, pp. 29-45, 2009. http://dx.doi.org/10.1080/03043790802710185

[8] J. J. Duderstadt, "Engineering for a changing world," in Holistic Engineering Education, ed: Springer, 2010, pp. 17-35.

[9] V. S. Lee, "What is inquiry-guided learning?," New directions for teaching and learning, vol. 2012, pp. 5-14, 2012. http://dx.doi.org/10.1002/tl.20002

[10] G. Yakman, "STEAM education: An overview of creating a model of integrative education," presented at the Pupils' Attitudes Towards Technology (PATT-19) Conference: Research on
Technology, Innovation, Design \& Engineering Teaching, Salt Lake City, Utah, USA, 2008.

[11] G. A. Boy, "From STEM to STEAM: Toward a Human-Centered Education, Creativity \& Learning Thinking," presented at the European Conference on Cognitive Ergonomics (ECCE 2013 ), Université Toulouse le Mirail, France, 2013.

[12] C. Kerr and C. Lloyd, "Pedagogical learnings for management education: Developing creativity and innovation," Journal of Management and Organization, vol. 14, pp. 486-503, 2008. http://dx.doi.org/10.5172/jmo.837.14.5.486

[13] A. M. Connor, S. Karmokar, C. Whittington, and C. Walker, "Full STEAM ahead: a manifesto for integrating arts pedagogics in to STEM education," presented at the IEEE International Conference on Teaching, Assessment and Learning for Engineering, Wellington, New Zealand, 2014. http://dx.doi.org/10.1109/tale.2014.7062556

[14] M. Jollands, L. Jolly, and T. Molyneaux, "Project Based Learning as a Contributing Factor to Graduates' Work Readiness," European Journal of Engineering Education, vol. 37, pp. 143154, 2011. http://dx.doi.org/10.1080/03043797.2012.665848

[15] N. Scott, R. Hadgraft, and V. Ilic, "Engineering Education- Is Problem Based or Project Based Learning the Answer?," The Australasian Association for Engineering Education, pp. 2-16, 2003.

[16] S. Karmokar and A. Shekar, "The Application Of Design Methods In Projects to Enhance Student Engagement," in Australasian Association for Engineering Education, Wellington, NZ, 2014.

[17] R. C. Schank, Dynamic Memory: A Theory of Reminding and Learning in Computers and People: Cambridge University Press, 1983.

[18] P. A. Johnson, "Problem-based, cooperative learning in the engineering classroom," Journal of Professional Issues in Engineering Education and Practice, vol. 125, pp. 8-11, 1999. http://dx.doi.org/10.1061/(ASCE)1052-3928(1999)125:1(8)

[19] M. J. O'Grady, "Practical Problem-Based Learning in Computing Education," ACM Transactions on Computing Education, vol. 12, pp. 1-16, 2012. http://dx.doi.org/10.1145/2275597.2275599

[20] M. J. Prince and R. M. Felder, "Inductive teaching and learning methods: Definitions, comparisons, and research bases," Journal of engineering education, vol. 95, pp. 123-138, 2006. http://dx.doi.org/10.1002/j.2168-9830.2006.tb00884.x

[21] R. M. Felder and L. K. Silverman, "Learning and teaching styles in engineering education," Engineering education, vol. 78, pp. 674-681, 1988.

[22] C. L. Dym, A. M. Agogino, O. Eris, D. D. Frey, and L. J. Leifer, "Engineering design thinking, teaching, and learning," Journal of Engineering Education, vol. 94, pp. 103-120, 2005. http://dx.doi.org/10.1002/j.2168-9830.2005.tb00832.x

[23] R. C. Schank, T. R. Berman, and K. A. Macpherson, "Learning by doing," Instructional-design theories and models: A new paradigm of instructional theory, vol. 2, pp. 161-181, 1999. http://dx.doi.org/10.1017/cbo9780511527920.011

[24] E. De Graaf and A. Kolmos, "Characteristics of problem-based learning," International Journal of Engineering Education, vol. 19 , pp. 657-662, 2003.

[25] A. Colburn, "An inquiry primer," Science scope, vol. 23, pp. 4244, 2000.

[26] J. Perrenet, P. Bouhuijs, and J. Smits, "The suitability of problem-based learning for engineering education: theory and practice," Teaching in higher education, vol. 5, pp. 345-358, 2000. http://dx.doi.org/10.1080/713699144

[27] G. Boy, "What Space can contribute to Global Science, Technology, Engineering, and Mathematics (STEM) Education," presented at the 63rd International Astronautical Congress, Naples, Italy, 2012.

[28] A. M. Connor, S. Karmokar, and C. Walker, "Doing entrepreneurship: Towards an entrepreneurial method for design and creative technologies," presented at the DesignEd Asia Conference, Hong Kong, 2014.

[29] N. E. D. Herrmann, "The Creative Brain*," The Journal of Creative Behavior, vol. 25, pp. 275-295, 1991. http://dx.doi.org/10.1002/j.2162-6057.1991.tb01140.x

[30] W. Stouffer, J. S. Russell, and M. G. Oliva, "Making the strange familiar: Creativity and the future of engineering education," in 
PAPER

From STEM TO STEAM: STRATEGIES FOR ENHANCING ENGINEERING \& TECHNOLOGY EDUCATION

Proceedings of the 2004 American Society for Engineering Education Annual Conference \& Exposition, 2004, pp. 20-23.

[31] T. F. Peters, "How creative engineers think," Civil Engineering$A S C E$, vol. 68, pp. 48-51, 1998.

[32] R. M. Felder, "On creating creative engineers," Engineering education, vol. 77, pp. 222-227, 1987.

[33] J. Bordogna, E. Fromm, and E. W. Ernst, "Engineering Education: Innovation Through Integration," Journal of Engineering Education, vol. 82, pp. 3-8, 1993. http://dx.doi.org/10.1002/j.2168-9830.1993.tb00065.x

[34] A. M. Connor, S. Marks, and C. Walker, "Creating creative technologists: Playing with (in) education," in Creativity in the Digital Age, N. Zagalo and P. Branco, Eds., ed Berlin: Springer, 2015.

[35] J. Lackney. (1999, 12th September 2014). A history of the studiobased learning model. Available: http://www.edi.msstate.edu/ work/pdf/history_studio_based_learning.pdf

[36] J. Piaget, The construction of reality in the child. London: Routledge, 1954. http://dx.doi.org/10.1037/11168-000

[37] R. J. Roselli and S. P. Brophy, "Experiences with formative assessment in engineering classrooms," Journal of Engineering Education, vol. 95, pp. 325-333, 2006. http://dx.doi.org/10.1002/j.2168-9830.2006.tb00907.x

[38] N. H. Narayanan, C. Hundhausen, D. Hendrix, and M. Crosby, "Transforming the CS classroom with studio-based learning," in Proceedings of the 43rd ACM technical symposium on Computer Science Education, 2012, pp. 165-166. http://dx.doi.org/10.1145/2157136.2157188

[39] P. Little and M. Cardenas, "Use of "studio" methods in the introductory engineering design curriculum," Journal of Engineering Education, vol. 90, pp. 309-318, 2001. http://dx.doi.org/10.1002/j.2168-9830.2001.tb00610.x

[40] D. Maor, "Pushing beyond the comfort zone: Bridging the gap between technology and pedagogy," presented at the Proceedings of the 21 st ASCILITE Conference, Perth.

[41] E. L. Thorndike, The fundamentals of learning. New York: AMS Press Inc., 1932. http://dx.doi.org/10.1037/10976-000

[42] E. Belbin, S. Downs, and B. Moore, "Unlearning'and its relationship to age," Ergonomics, vol. 7, pp. 419-427, 1964. http://dx.doi.org/10.1080/00140136408930759

[43] G. Gibbs and M. Coffey, "The impact of training of university teachers on their teaching skills, their approach to teaching and the approach to learning of their students," Active learning in higher education, vol. 5, pp. 87-100, 2004. http://dx.doi.org/10.1177/1469787404040463

[44] M. Lunenberg, F. Korthagen, and A. Swennen, "The teacher educator as a role model," Teaching and Teacher Education, vol. 23 , pp. 586-601, 7// 2007.
[45] A. M. Connor, J. Buchan, and K. Petrova, "Bridging the researchpractice gap in requirements engineering through effective teaching and peer learning," in Sixth International Conference on Information Technology: New Generations (ITNG'09), 2009, pp. 678-683. http://dx.doi.org/10.1109/itng.2009.134

[46] P. A. Kirschner, J. Sweller, and R. E. Clark, "Why minimal guidance during instruction does not work: An analysis of the failure of constructivist, discovery, problem-based, experiential, and inquiry-based teaching," Educational psychologist, vol. 41, pp. 75-86, 2006. http://dx.doi.org/10.1207/s15326985ep4102 1

[47] J. Foottit, D. Brown, S. Marks, and A. M. Connor, "An Intuitive Tangible Game Controller," presented at the 10th Australasian Conference on Interactive Entertainment, Newcastle, Australia, 2014. http://dx.doi.org/10.1145/2677758.2677774

[48] R. Spronken-Smith, J. Bullard, W. Ray, C. Roberts, and A. Keiffer, "Where might sand dunes be on Mars? Engaging students through inquiry-based learning in geography," Journal of Geography in Higher Education, vol. 32, pp. 71-86, 2008. http://dx.doi.org/10.1080/03098260701731520

[49] S. K. Card, J. D. Mackinlay, and G. G. Robertson, "A morphological analysis of the design space of input devices," ACM Trans. Inf. Syst., vol. 9, pp. 99-122, 1991. http://dx.doi.org/10.1145/123078.128726

[50] S. Pugh, Total Design. New York: Addison-Wesley, 1990.

\section{AUTHORS}

A. M. Connor is with Colab, the interdisciplinary collaboratory at Auckland University of Technology, Auckland, New Zealand. He holds a B.Eng. degree in Mechanical Engineering and a Ph.D. in Mechatronics. (e-mail: andrew.connor@aut.ac.nz).

S. Karmokar is with Colab, the interdisciplinary collaboratory at Auckland University of Technology, Auckland, New Zealand. (e-mail: sangeeta.karmokar@ aut.ac.nz).

C. Whittington is with the School of Engineering at Auckland University of Technology, Auckland, New Zealand. (e-mail: chris.whittington@ aut.ac.nz).

This article is an extended and modified version of a paper presented at the 2014 IEEE International Conference on Teaching, Assessment and Learning for Engineering (TALE2014), held 8-10 December, Te Papa Tongarewa National Museum of New Zealand, Wellington, New Zealand.Submitted, February, 17, 2015. Published as resubmitted by the authors on May, 07, 2015. 